\title{
Video Self-Modeling on an iPad to Teach Functional Math Skills to Adolescents with Autism and Intellectual Disability
}

\author{
Cami Elizabeth Burton \\ Brigham Young University - Provo, camiburton88@gmail.com \\ Darlene Anderson \\ darlene_anderson@byu.edu \\ Mary Anne Prater \\ Brigham Young University - Provo, prater@byu.edu \\ Tina Taylor \\ Brigham Young University, tina_taylor@byu.edu \\ Follow this and additional works at: https://scholarsarchive.byu.edu/facpub \\ Part of the Counseling Psychology Commons, and the Special Education and Teaching Commons
}

\section{Original Publication Citation}

Burton, C. E., Anderson, D. H., Prater, M. A., \& Dyches, T. T. (2013). Video self-modeling on an iPad to teach functional math skills to adolescents with autism and intellectual disability. Focus on Autism and Other Developmental Disabilities, 28(2), 67-77. doi:10.1177/1088357613478829

\section{BYU ScholarsArchive Citation}

Burton, Cami Elizabeth; Anderson, Darlene; Prater, Mary Anne; and Taylor, Tina, "Video Self-Modeling on an iPad to Teach Functional Math Skills to Adolescents with Autism and Intellectual Disability" (2013). Faculty Publications. 1559.

https://scholarsarchive.byu.edu/facpub/1559

This Peer-Reviewed Article is brought to you for free and open access by BYU ScholarsArchive. It has been accepted for inclusion in Faculty Publications by an authorized administrator of BYU ScholarsArchive. For more information, please contact ellen_amatangelo@byu.edu. 
Running Head: VIDEO SELF-MODELING TO TEACH MATH SKILLS

Video Self-Modeling on an iPad to Teach Functional Math Skills to Adolescents with Autism and Intellectual Disability

Cami E. Burton, MS

Darlene H. Anderson, PhD

Mary Anne Prater, $\mathrm{PhD}$

Tina T. Dyches, $\mathrm{PhD}$

Brigham Young University

FULL CITATION:

Burton, C. E., Anderson, D. H., Prater, M. A., \& Dyches, T. T. (2013). Video self-modeling on an iPad to teach functional math skills to adolescents with autism and intellectual disability. Focus on Autism and Other Developmental Disabilities, 28(2), 67-77. doi:10.1177/1088357613478829 


\begin{abstract}
Research suggests that video-based interventions can provide increased opportunity for students with disabilities to acquire important academic and functional skills; however, little research exists regarding video-based interventions on the academic skills of students with autism and intellectual disabilities. The current study used a multiple baseline design across participants to investigate the effects of video self-modeling (VSM) on the mathematics skill acquisition of adolescents with autism. Four adolescent male students viewed videos of themselves on an iPad solving mathematical problems to estimate the amount of money used to pay for a given item and the amount to receive in change. Findings support a functional relationship between video self-modeling and performance on math skills for each participant, confirming previous studies indicating that VSM is an effective instructional tool for students with autism and intellectual disabilities. The current study extends prior research by teaching a mathematical skill to this population of students.
\end{abstract}

Keywords: autism, intellectual disabilities, video self-modeling, functional mathematics instruction, iPad 
Video Self-Modeling Presented via an iPad to Teach Functional Math Skills to Adolescents with Autism and Intellectual Disabilities

Instructional strategies involving the use of video modeling have been shown to be highly effective in teaching new skills to children with autism spectrum disorders (ASD), even at the earlier stages of skill acquisition (Cihak, Fahrenkrog, Ayres, \& Smith, 2010). This finding is unsurprising in view of the extensive body of research documenting the visual strengths of this group, as well as their aptitude for performing visuospatial tasks. Alternatively, youth with ASD often experience difficulty in engaging in reciprocal social interaction; they likewise tend to struggle with communication, change in routines, and self-stimulatory behavior (American Psychiatric Association [APA], 2000).

The education of children with autism in inclusive environments is becoming more widespread (Cihak, et al., 2010). For example, recent data provided by the U.S. Department of Education documented a $77 \%$ increase in the number of students with autism receiving services in general education classrooms between 1997 and 2006 (U.S. Department of Education, 2008). This statistic -- representing a 14 percentage-point increase over a nine-year period -- may be due in part to the broader spectrum of autism being identified; it is likewise common for students with high functioning autism and Asperger syndrome to receive educational services alongside their non-disabled peers. Due to the greater variability in functioning among children with ASD, research is needed to identify interventions appropriate to an increasingly diverse population. Moreover, investigations assessing the effects of instructional strategies to help students with disabilities access the core curriculum are recommended in the literature (Knight, Smith, Spooner, \& Browder, 2011). 


\section{The Promise of Technology}

Studies have shown that technology can increase opportunities for students with disabilities to access the core curriculum and achieve improved learning outcomes (Cihak \& Bowlin, 2009). Current advances in the use of technology in classrooms have included new applications of video technology (Mechling, 2005). Video modeling is an example successfully applied to mathematics instruction for students with learning disabilities (Cihak \& Bowlin, 2009). Video modeling (VM) is an instructional technique that involves a student watching a video of a model (e.g., a peer or adult) engaging in target behaviors or skills, with the student later performing the same skills (Cihak et al., 2010). Video self-modeling (VSM) is a specific application of video modeling, in which the individual observes herself accurately and independently performing the target behavior (Dowrick, 1999). It is a form of observational learning in which individuals view themselves performing a task at a more advanced level than they typically perform the skill (Buggey, Toombs, Gardener, \& Cervetti, 1999). VSM has been used to teach a variety of skills including transitional behaviors (Cihak et al., 2010); socialcommunication, behavioral, and functional/life skills (Bellini \& Akullian, 2007; Buggey, 2007); perspective taking (Charlop-Christy \& Daneshvar, 2003); communication, behavior, and academic performance (Hitchcock, Dowrick, \& Prater, 2003).

The effects of VSM have been assessed with students with emotional disturbances (e.g., Possell, Kehle, McLoughlin, \& Bray, 1999), learning disabilities (e.g., Clare, Jenson, Kehle, \& Bray, 2000), general education students (e.g., Hartley, Bray, \& Kehle, 1998), students with intellectual disabilities (e.g., Cihak, Kessler, \& Alberto, 2007), and autism spectrum disorders (e.g., Shipley-Benamou, Lutzker, \& Taubman, 2002). Video self-modeling has been delivered through several media including (a) television and videocassette recorder, (b) laptop computer, 
(c) DVD, and (d) handheld device (e.g., video iPod) (Cihak et al., 2010). Handheld computers are one form of technology that has been shown to be effective for the delivery of VSM to individuals with disabilities in various settings (Cihak \& Bowlin, 2009; Cihak et al., 2010).

\section{Using Technology to Enhance Math Instruction}

Youth with disabilities are in need of instruction incorporating a blend of academic and functional math objectives (Browder \& Cooper-Duffy, 2003). Functional math focuses on teaching practical mathematics within real-life situations such as telling time, using money, and completing tasks related to measurement. Schunk and Hanson (1989) used VSM to teach math concepts to elementary school students working below grade level in the subject area. Schunk and Hanson's study strengthened the evidence suggesting that VSM can increase students' academic performance during cognitive skill training. Particular findings indicated that students who viewed themselves successfully completing math problems performed at higher levels than students who did not watch the self-model. However, additional research is needed to examine the use of VSM and handheld devices to teach mathematics to students with disabilities.

The purpose of the current study was to examine the effects of VSM on the mathematics performance of adolescent students with autism and intellectual disabilities receiving functional skills instruction in a self-contained special education classroom. Given specific behavioral objectives involving estimating and counting exact change, two main research questions were addressed:

1. During the intervention phase, in the presence of a five-item exemplar, what are the effects of VSM via an iPad on the percentage of correct responses? 
2. During post-intervention phases one through five, in the presence of similar but different stimuli (i.e., the inclusion of novel math problems), what are the effects of VSM via an iPad on percentage of correct responses?

Over the past two decades, opportunities for students with developmental disabilities, including autism and intellectual disabilities to participate more fully in the core curriculum have greatly increased. In addition, there exists a greater focus on individual strengths and fostering independence in the presence of high expectations for students with disabilities. Important outcomes include the acquisition of functional, adaptive, daily living, and social skills, and to gain the competencies necessary to achieve the highest level of independence possible. These outcomes are particularly critical for students with autism and intellectual disabilities. The intent of the video-based intervention evaluated in the current study was to support the acquisition of a new academic skill by focusing on learning strengths.

\section{Methods}

\section{Participants}

After receiving approval from the university and school district institutional review boards for research involving human subjects, four male students given the pseudonyms of Joey, Will, Ryan, and Aaron were selected to participate in the study. Each of the parents provided written consent. The university's institutional review board waived the need to obtain student assent.

Participant selection was based on the following criteria: (a) junior high school enrollment, (b) disability based on eligibility requirements, (c) similar assessment results from selected math subtests of the BRIGANCE® Comprehensive Inventory of Basic Skills-Revised (CIBS-R; Brigance, 1999), (d) IEP math goals and objectives similar to the learning objective 
for the current study, (e) parental permission to participate in the study, including videotaping, (f) no hearing or vision impairments that might impede video instruction, and (g) functional reading skills, i.e., ability to read the math story problems without additional instruction (selection criteria adapted from Cihak \& Bowlin, 2009). Additional information regarding the participants' cognitive ability and reading levels is displayed in Table 1.

Ryan, Aaron, and Will received daily mathematics instruction in a self-contained special education classroom. Joey received daily mathematics instruction in a resource pre-algebra math class with seven students; he also received additional functional mathematics instruction in the self-contained special education classroom. More specific information about each student follows.

Joey. Joey was a verbal 13-year-old Caucasian student with autism. The Universal Nonverbal Intelligence Test (UNIT; Bracken, \& McCallum, 1998) indicated an IQ of 85. The UNIT is administered nonverbally and requires nonverbal responses. Joey's composite scores were in the average to low average range. During study implementation, Joey attended three resource classes (math, reading, and writing), two general education classes (career introduction and chorus), and two life skills self-contained classes (life skills math and social skills). In the classroom, Joey was pleasant and compliant; he often needed several redirections and prompts to focus on an activity. According to the Brigance Reading Comprehension Inventory of Basic Skills, Joey was able to comprehend text on an upper $3^{\text {rd }}$ grade level with $100 \%$ accuracy on a $4^{\text {th }}$ grade level with $80 \%$ accuracy, with teacher prompting. The Dynamic Indicators of Basic Early Literacy Skills (DIBELS; Good \& Kaminski, 2002) assessment indicated Joey was reading $4^{\text {th }}$ grade level text at a rate of 187 words per minute with $99 \%$ accuracy. 
Will. Will, the second participant, was a verbal 14-year-old Caucasian student with autism. The Universal Nonverbal Intelligence Test (UNIT) indicated an IQ of 76. Will's scores were in the borderline range for intellectual disability. Will attended two general education classes (career introduction and chorus) with a paraeducator and spent the remainder of the school day in a life skills self-contained classroom. Will had limited verbal ability and was often echolalic in his speech. Yet, Will was very compliant; he preferred to look at books or sit quietly rather than to interact with his classmates. According to the Dynamic Indicators of Basic Early Literacy Skills (DIBELS; Good \& Kaminski, 2002), Will was reading a ${ }^{\text {rd }}$ grade level text at 61 words per minute with $97 \%$ accuracy. In his IEP, recalling information from stories read was noted as an area of difficulty.

Ryan. The third participant, Ryan, was a 15-year-old Caucasian male with autism. The Woodcock Johnson III Tests of Cognitive Ability (WJ-III; Woodcock, McGrew, \& Mather, 2001) indicated a full scale IQ of 61. Overall, Ryan's scores were in the very low range. Ryan also had an adaptive behavior assessment indicating he had an intellectual disability. Even though the cognitive score results suggested several areas of strength, Ryan clearly qualified for special education services within the intellectual disability category, based on the multidisciplinary team's decision. However, parental consent for this classification was denied, and additional testing justified educational classification in the autism category. Ryan attended three general education classes (foods, peer-tutoring, and manufacturing) with a paraeducator. He spent the remainder of the school day in a life skills self-contained classroom. Ryan was provided a Behavior Intervention Plan (BIP) due to frequent displays of verbal and physical aggression. Despite difficulties in some social situations in school, Ryan seemed to enjoy interacting with adults and peers. According to the Dynamic Indicators of Basic Early Literacy 
Skills (DIBELS; Good \& Kaminski, 2002), Ryan was reading $3^{\text {rd }}$ grade level text at 64 words per minute with $98 \%$ accuracy. In his IEP, recalling information from stories read was noted as an area of strength.

Aaron. Aaron, the fourth participant, was a 13-year-old Caucasian student with intellectual disabilities. The Wechsler Intelligence Scales for Children IV (WISC IV; Wechsler, 2003) indicated a full scale IQ of 66. As was the case with Ryan, Aaron's scores fell in the very low range. During the study, Aaron attended one resource class (reading), and three general education classes (career introduction, art, and chorus) with a paraeducator or a peer-tutor. He spent the remainder of the school day in a life skills self-contained classroom. Aaron struggled to attend and stay on task in class; he often looked around the classroom or attempted to talk to other students. Aaron was also friendly and outgoing and appeared to get along well with other students in the class. According to the Dynamic Indicators of Basic Early Literacy Skills (DIBELS; Good \& Kaminski, 2002), Aaron was reading $3^{\text {rd }}$ grade level text at 130 words per minute with $99 \%$ accuracy. Aaron also scored at a $3^{\text {rd }}$ grade level in reading comprehension. In his IEP, reading was noted as an area of strength.

\section{Participant Selection Measures}

Two measures were used in selecting participants for the study. First, the Brigance Comprehensive Inventory of Basic Skills - Revised (CIBS-R; Brigance, 1999) was used to assess math skill. The Brigance (CIBS-R) is a criterion-referenced classroom assessment for children between the ages of 5 and 13, recommended for planning individual instruction. It consists of 154 assessments in eight areas, including Readiness, Speech, Listening, Reading, Spelling, Writing, Research and Study Skills, and Mathematics. The current edition allows users to make norm-referenced interpretations regarding student performance. Scores correlate 
moderately well with the Wechsler Intelligence Scale for Children. Validity evidence is reported for the first time, and analyses of reliability have shown test-retest correlations to exceed .80. In summary, the CIBS-R is an improved revision of a standard curriculum-based assessment that is widely used by teachers to document elementary and middle school students' mastery of specific skills (Cizek, 2001).

The classroom teacher evaluated students' money skills using the following sub-tests from the Brigance (CIBS-R): recognizes money, equivalent values of coins and the dollar bill, total values of groups of coins (adds), converts coins, and makes change. During testing, an adapted version of the Brigance Assessment Fidelity Checklist was used to help ensure assessment integrity. The checklist included only items relevant to the pre-assessment. The results of the Brigance assessment indicated an instructional need within the sub-test category of total values of groups of coins (adds). More specifically, Joey was able to recognize cents, nickels, dimes, and quarters, Will and Aaron were able to recognize cents, nickels, and dimes, and Ryan was able to recognize cents and nickels. In the sub-test category, equivalent values of coins and the dollar bill, Joey and Will scored (4/9), Ryan scored (8/9), and Aaron scored (7/9). In the category, $C B M-$ Exact Change (up to \$25.00), Joey scored (4/5), Will and Aaron scored $(0 / 5)$, and Ryan scored (1/5).

Secondly, to pinpoint the instructional level, a curriculum-based assessment was administered to determine students' accuracy while reading a price tag and giving exact change, using the fewest possible bills and coins. The curriculum-based assessment included five items and five price tags. The prices listed on the curriculum-based assessment were $\$ 2.37, \$ 19.54$, $\$ 7.18, \$ 22.07$, and $\$ 12.89$. Results of the curriculum-based assessment for all participants ranged from $0 \%$ to $20 \%$, indicating a need for math instruction in the area assessed. 


\section{Setting}

The study was conducted in a junior high school of approximately 1200 students in a suburban neighborhood in the western part of the United States. The special education classroom consisted of 10 students, five boys and five girls, with disabilities including autism, multiple disabilities, intellectual disabilities, other health impairment, and emotional disturbance. Adults working in the classroom included one licensed special education teacher, two classroom paraeducators, and one paraeducator assigned to a specific student. Baseline, intervention, and post-intervention phases of the study occurred in a partitioned section of the special education classroom.

Prior to the intervention, math instruction consisted of delivering math content individually or in small groups. Materials included manipulatives, worksheets, and learning activities. A token economy featuring reward charts and simulated money was used to reinforce desired behavior. Possible rewards included five minutes of free time on an iPad. By this means, students were able to familiarize themselves with the iPad prior to the commencement of the study.

\section{Materials}

All videos were created using a Panasonic HM-TA1 flip video camcorder and Windows Live Movie Maker software. Five videos were developed for each participant using video feedforward (Dowrick, 1999) to show the individual students successfully completing five story problems. Following the editing of each video, the five videos per student were loaded onto a 16 GB Apple iPad for viewing. A cash drawer also contained specified simulated money. At the beginning of each instructional session, students were given a worksheet with story problems relating to functional math, scratch paper, and a pencil. 


\section{Response Measurement and Data Collection}

Students were instructed to estimate the amount they should use to purchase a particular item and the amount of change they should receive back. The purpose of the instruction was to help ensure honest treatment by merchants in real-life settings.

The learning objective was related to the common core state mathematics standards for seventh graders, standard 7.EE, "solve real life and mathematical problems using numerical and algebraic expressions and equations" (“Common Core State Standards for Mathematics”, n.d., p. 47). The standard suggests that students need to understand how to solve functional multi-step math problems, convert between mathematical forms, and use mental computation and estimation. Essential math skills linked to the common core were assessed by recording the dependent variable, i.e., the percentage of steps completed accurately and independently. The assessment aligned with the learning objective written below:

Given five story problems using specific price tags $(\$ 3.49, \$ 8.68, \$ 14.82, \$ 17.13$, and $\$ 24.53)$; a cash register containing simulated money consisting of two $\$ 20$ bills, four $\$ 10$ bills, five $\$ 5$ bills, $25 \$ 1$ bills, 10 quarters, 20 dimes, 30 nickels, and 50 pennies; scratch paper; and a pencil, students will estimate, calculate, and show the exact change with at least $80 \%$ accuracy over at least three consecutive sessions, using the following steps:

- Read the story problem or watch the video model on the iPad.

- Identify the cost of the item listed on the price tag by circling the price.

- Estimate the amount to be paid using the smallest number of bills by writing the estimate.

- Give the money to the teacher. 
- Estimate about how much change you should get back (within $\$ 0.50$ ) by writing the estimate.

- Calculate and write the exact amount you should get back.

- Use the cash register to make exact change using the fewest possible bills and coins. To record student performance, the teacher used a scoring form listing all of the steps of the task analysis for each of the problems. The scoring procedure was integral to the study's dependent variable, i.e., the percentage of steps participants completed correctly. The teacher likewise documented the number of times the student watched the VSM on the scoring form.

\section{Interobserver Agreement}

Each instructional session was videotaped. To conduct the reliability checks, the first author (primary coder) and a second coder independently viewed one third of the sessions in baseline, intervention, and post-intervention phases. To achieve acceptable levels of agreement, the two coders discussed the scoring criteria in detail and the second coder practiced the scoring procedure. The two coders then independently scored three work samples, achieving an agreement index of $100 \%$. The observer scoring records were compared item by item and an agreement was tallied if both coders recorded identical scores. Point-by-point percentage agreement (Kazdin, 1982) was calculated by dividing the number of agreements by the number of agreements plus disagreements and multiplying by 100. The percentage of agreement in baseline, intervention, and post-intervention phases for all study participants was $100 \%$.

\section{Experimental Design}

Experimental effects were evaluated within a multiple baseline across participants design. Baseline data were initially gathered on the dependent variable, percentage of correct responses, for each of the four students. When all baseline data were stable with respect to level and trend, 
the intervention was applied to the first baseline series while baseline conditions were continued for the other participants. When the behavior of the first student reached the criterion level as defined in the learning objective ( $80 \%$ accuracy over at least three consecutive sessions), the intervention was implemented with the second student. This procedure was followed until all of the participants had received the intervention.

\section{Experimental Procedures}

In addition to baseline, intervention and post-intervention phases, an additional nonexperimental phase involved the development of the video self-model, occurring between baseline and intervention phases. Math problems presented in the baseline phase differed from those assessed during the intervention phase. However, problems presented in both phases were assumed to be of similar difficulty because they were kept within the same price range. The classroom teacher additionally tried to anticipate the change participants would be expected to make to assure the use of similar coins across baseline and intervention phases. The five problems comprising the baseline assessment were changed every three sessions to prevent participants from becoming too familiar with (or overly frustrated by) the high demand task. During baseline and intervention phases, participants received daily assessment and/or instruction in approximately 20-30 minute sessions four to eight times per week. The worksheets used consisted of step-by-step instructions and five one-sentence story problems with the solution of each problem encompassing seven distinct steps.

Positive reinforcement, i.e., verbal praise and a classroom token economy, were applied in baseline, intervention and post-intervention phases. Because the purpose of the study was to test the effects of VSM alone, rather than to assess the impact of a multi-component treatment package, participants were praised for engaging in appropriate behavior, but no praise was 
delivered for improved academic performance; additionally, neither prompts nor error correction procedures were used. Examples of behavior praise statements included, "I like the way you are following directions," and "Great working!" The token economy implemented in the special education classroom allowed students to earn 5 stars for working prior to selecting the reward of their choice. Free-reading time, pretend quarters to be used in the class store, listening to music, helping the teacher, swinging, choosing a friend to sit by, and playing a game were back-up reinforcer options.

Baseline. The first author (classroom teacher) trained two paraeducators in implementation procedures prior to the beginning of the study. The training occurred over a period of approximately one week in five 30-minute sessions. During baseline, either the classroom teacher or the paraeducator worked one-on-one with each student and presented five story problems similar to those presented during the intervention phase. The teacher directed the student to read the story problem and follow the directions listed on the worksheet. The teacher did not instruct or give feedback regarding the accuracy of the student's response.

Video development. To develop the videos, the teacher turned on the video recorder, presented each student with a script of the seven steps of the task analysis and prompted each student as necessary in reading the steps and solving the story problems while being videotaped. The teacher provided the level of prompting needed to ensure accurate completion of the story problem. The script listed all seven steps of the task analysis and contained exact statements to be read by the students. Each participant was required to solve five math problems, resulting in five video self-models representing the problems to be solved. The videos were edited to eliminate teacher prompts and ranged in length from approximately three to five minutes. Data were not collected during the video development phase because only one session was needed. 
Intervention: Math instruction via VSM. The intervention procedures were implemented twice daily, four days a week. After turning on the video recorder on the iPad, the student watched himself complete one problem. He could then pause the video, fast-forward, or rewind as necessary to solve the same problem on paper. This procedure was followed for each of the five problems presented. The VSM intervention was implemented without the teacher's assistance. The teacher's role was to record student performance, collect treatment fidelity data, and praise appropriate behavior. Intervention procedures were continued until the criterion level of performance was achieved and maintained for at least three consecutive sessions.

Post-intervention. Post-intervention consisted of six individual phases. During the post-intervention phase, a fading procedure was used to reduce the number of video models provided to the student over time. This was accomplished by requiring the participants to complete one novel problem without a video model while gradually removing the model for previously solved problems.

In phase one, the video model was provided for four previously solved problems while one novel problem was introduced and answered without the video model. The VSM was gradually removed for the problems in subsequent phases, until post-intervention phase five when participants were expected to solve all five problems without the video model.

In post-intervention phase six, the student was presented with the same five problems assessed during the intervention phase. The purpose of this phase was to determine whether the participant could successfully solve the previously practiced problems, given the lapse in time, without the use of the video model. Although the video model was eventually removed, visual prompts, i.e., the seven steps needed to complete each problem, were listed on the worksheets for 
the duration of the study. Having the opportunity to access the seven steps allowed the students to independently prompt themselves.

Following the completion of post-intervention phase six, student performance was examined in three weekly probes. Video modeling was removed during follow-up and the math problems presented were identical to those evaluated during the intervention phase.

\section{Data Analysis}

Visual analysis and effect size were used to analyze and interpret the results of the study. Using a line graph, individual student performance was recorded and analyzed daily in baseline, intervention, and post-intervention phases. Changes in level, trend, and variability were carefully noted across and within conditions and were important indicators of an experimental effect. Baseline, intervention, and post-intervention averages were also calculated and compared. The research objective was to demonstrate a functional relation between the dependent variable (percentage of correct responses) and independent variable (VSM) by observing a systematic change in student performance that occurred at the same time the intervention was introduced.

Treatment fidelity. The teacher assessed treatment fidelity using a checklist for each phase of the study as well as the set-up. She collected data on all steps of the task-analysis for each intervention session and an independent observer recorded data during $33 \%$ of the intervention phases. Treatment fidelity measures verified the teacher's use of the instructional task analysis, which included providing the iPad to the student, prompting the student to activate the device, and collecting data. Measures likewise confirmed that all materials were set up properly and the teacher was recording data. 
Social validity. Social validity was assessed using two versions of an open-ended, fourquestion survey. The surveys evaluated participants' satisfaction with goals, procedures, and outcomes of the study (Wolf, 1978). The first survey was administered to research assistants involved in the study's implementation; the second was administered to student participants. The classroom teacher distributed the surveys and assumed the students could read and understand the questions; she offered an explanation if a student asked for one. (Ryan asked one or two questions. Other participants answered the questions independently.)

\section{Results}

Effects of VSM via an iPad on the math performance of adolescent students with autism and intellectual disabilities were evaluated using a multiple baseline design across four participants in baseline, intervention, and post-intervention phases. The dependent variable, percentage of correct responses, reflected a functional relationship between VSM and accuracy of math calculation for all four participants during the calculation of five math problems during the intervention phase and math problems that varied during post-intervention phases one through five.

\section{Participant Scores}

Figure 1 shows the effect of VSM on the percentage of steps that each student solved accurately and independently using a worksheet containing five story problems and a list of seven steps to be used in solving the problems. Figure 1 data, including baseline, intervention, and post-intervention measurements, are summarized below.

Joey. During baseline, Joey read the story problems out loud and occasionally circled the correct price, completing at the most two out of the seven steps required to solve the problem. 
Baseline data were somewhat variable with a slight downward trend. The mean percentage of steps solved correctly during baseline was $24 \%$ with a median of $26 \%$ and range of $16-28 \%$.

At the beginning of intervention, the change in level was immediate and pronounced. Intervention data were slightly variable with a consistent upward trend. The mean percentage of steps solved correctly during intervention was $98 \%$. The increase in the percentage of steps solved correctly during intervention was $74 \%$. The percentage of data points exceeding the median (PEM) of baseline phase was 100\% (Parker, Vannest, \& Brown, 2009). The range of values in intervention was $91-100 \%$. The percentage of non-overlapping data (PND) (Tawney \& Gast, 1984) in baseline and intervention phases was $100 \%$. The improvement rate difference (IRD) or effect size was 1.00 (Parker et al., 2009).

The mean percentage of steps completed correctly across the first five post-intervention phases was $98.8 \%$. The mean percentage correct for post-intervention phase six was $100 \%$. Results of three weekly probes all reached $100 \%$.

Will. During baseline, Will read the story problems out loud, completing at the most one out of the seven steps required to solve the problem. Baseline data revealed no downward or upward trend. All baseline values equaled 14\%. After intervention was initiated, the change in level was immediate and pronounced. Intervention data were stable with no downward or upward trend. The mean percentage of steps solved correctly during intervention was $100 \%$. The increase in the percentage of steps solved correctly during intervention was $86 \%$. The PEM, all data points, and PND were 100\%. The IRD or effect size was 1.00 .

The mean percentage of steps completed correctly across the first five post-intervention phases was $96.7 \%$; percentages for the sixth post-intervention phase averaged $90.3 \%$. Results of the weekly probes averaged $92.3 \%$ 
Ryan. During baseline, Ryan completed zero out of the seven steps required to solve the problem resulting in $0 \%$ correct. At the beginning of intervention, the change in level was immediate and pronounced. Intervention data were slightly variable with an upward trend. The mean percentage of steps solved correctly during intervention was $98.5 \%$. The increase in the percentage of steps solved correctly during intervention was $98.5 \%$. The PEM was $100 \%$. The range of values in intervention was $97-100 \%$. The PND in baseline and intervention phases was $100 \%$; and the IRD or effect size was 1.00 .

The mean percentage correct across the first five post-intervention phases was $93.2 \%$, while performance in post-intervention phase six averaged $85.8 \%$. Results of weekly probes indicated an overall average of $88 \%$.

Aaron. During baseline, Aaron read the story problems out-loud, completing at the most one out of the seven steps required to solve the problem. Baseline data revealed no downward or upward trend. All data points were 14\%. When the intervention began, the change in level was immediate and pronounced. Intervention data were slightly variable with no observed difference in trend in the final three data points. The mean percentage of steps solved correctly during intervention was $98.5 \%$. The increase in the percentage of steps solved correctly during intervention was $84.5 \%$. The PEM was $100 \%$. The range of values in intervention was 94100\%. The PND in baseline and intervention phases was $100 \%$; and the IRD or effect size was 1.00 .

The mean percentage of steps completely correctly during the first five post-intervention phases was $92.58 \%$, while post-intervention phase six scores averaged $87 \%$. Results of weekly probes indicated an average score of $79.6 \%$ 


\section{Stimulus Generalization}

Since the novel problems had not been previously introduced and the order in which these problems were presented in each of the five post-intervention phases varied, the first five of the six post-intervention phases allowed participants to transfer previous learning to an unfamiliar stimulus and to demonstrate flexibility of responding without the use of the video model. In terms of the dependent variable, percentage of correct responses, the results achieved in the assessment indicated varied degrees of stimulus generalization across individual participants.

To sort out the effects of test practice, the dependent variable was examined in relation to each participant's initial attempt to solve a novel problem. In this analysis, the mean percentage of steps completed correctly across the five post-intervention phases ranged from $82.8 \%$ (Joey) to $59.8 \%$ (Aaron) with an overall average of nearly $70 \%$ for the four participants.

\section{Social Validity and Treatment Fidelity}

Both paraeducators stated that they enjoyed participating in the study. Time and scheduling issues were the only challenging aspects noted. Each paraeducator reported seeing immediate progress in the students' performance during the intervention phase. One remarked, "I saw students using the iPad as a learning tool, and I saw firsthand that these students could remember each step." The other commented, "This study was amazing to me."

In their written comments, all student participants indicated that they liked having a video made of them in class and stated that they enjoyed watching a video of themselves. As Ryan affirmed, "It was cool and fun." Three of the four participants positively referenced the iPad. It was observed that without exception, all of the students seemed enthusiastic and excited to participate in the study each day. 
Treatment fidelity measures verified the teacher's use of the instructional task analysis during all phases of the study. Data confirmed that all materials were set up and intervention procedures accurately implemented $100 \%$ of the time.

\section{Discussion}

The purpose of the current research was to evaluate the effects of VSM via an iPad on the mathematics skill acquisition of adolescent students with autism and intellectual disabilities. Results of the study disclosed a functional relationship between dependent and independent variables over three replications of the VSM intervention. The dependent variable, percentage of correct responses, indicated marked improvement in participant performance only when the intervention was implemented and not before; intervention effects were similar during the study's follow-up phase, and the participants' ability to transfer learning to a novel stimulus was demonstrated in the first five post-intervention phases.

Similar to previous VM and VSM findings, the intervention applied in the current study was successful in teaching students with disabilities a new skill (e.g., Bellini \& Akullian, 2007; Buggey, 2007; Charlop-Christy \& Daneshvar, 2003; Cihak et al., 2010; Hitchcock et al., 2003). Results were likewise consistent with prior research showing improved math functioning of students with disabilities and students at risk for failure through the use of VM and VSM (Cihak \& Bowlin, 2009; Schunk \& Hanson, 1989). The data additionally substantiated previous VM and VSM research demonstrating continuous improved student performance across time (Bellini \& Akullian, 2007; Cihak \& Bowlin, 2009; Cihak et al., 2010). Finally, the study’s outcome confirmed previous research involving the use of handheld computers to promote student learning (e.g., Cihak \& Bowlin, 2009; Cihak et al., 2010). 
Results of the current study extended the previous VSM literature in a number of respects. First, the VSM intervention incorporated innovative instructional methodologies allowing students with disabilities who were receiving services in a self- contained special education classroom increased access to the core curriculum. Although many evidence-based practices have been previously identified (Browder \& Cooper-Duffy, 2003), the present research expanded the knowledge base in academic core instruction, specifically, through the use of VSM via an iPad, demonstrating the intervention's utility as a highly efficient aide to instruction. Second, the study extended the research by documenting the acquisition of a functional math skill clearly linked to the core curriculum (Browder \& Cooper-Duffy, 2003). Third, the study extended research involving the use of VSM to teach a mathematical skill to a new population of students, that is, adolescents with autism and intellectual disabilities.

\section{Limitations}

The single subject study was conducted with four participants, impacting the generalizability of the findings. Replications of the experimental effect would strengthen the external validity of the study. An additional limitation relates to the first author assuming the dual role of classroom teacher and researcher. Although the original intent was to involve the paraeducators according to a set schedule, near the beginning of the study, this involvement was discontinued. Even though data collection procedures did not appear to be compromised, the change was made due to concerns related to treatment fidelity. The paraeducators frequently asked the teacher questions about the procedures, interrupting classroom instruction. As a result, the paraeducators were only involved in approximately $20 \%$ of the total sessions, mostly during the baseline condition. 
Certain procedural limitations were also a factor in the current research. Part of the instructions on the worksheets stated, "Read the story problem" when they should have read, "Read the story problem out loud or watch the video." Changes were made to the worksheets after day one of baseline. During session two of the intervention phase, it was noted that Joey's video self-model contained a step that was incorrect. Additional filming and editing were required to correct the VSM for Joey. On one occasion during post-intervention phases, only the morning session was conducted due to the scheduling of school activities during the afternoon session. It is possible this change in routine may have had a subtle effect on participant performance. Because spring break occurred the seventh week of the ten-week study, the postintervention and/or follow-up phases were interrupted for all participants. Outcomes for certain students may have been adversely impacted.

Marked differences were noted between Joey and Aaron's performance during the fading procedure and follow-up probes. Although the two students made similar gains during the intervention phase, Aaron's post-treatment averages declined dramatically, falling to $87 \%$ and $79.6 \%$, respectively. In contrast, Joey's scores averaged $100 \%$, both during post-intervention phase six and follow-up. It is speculated that differences in the students' ability to retain and generalize information may have been related to uncontrolled factors, such as differences in aptitude. For example, Joey's level of intellectual functioning was reported to be in the "low to average" range, while Aaron's full-scale IQ fell in the "borderline" range of intelligence. Additionally, Aaron's working memory was estimated to be at the $4^{\text {th }}$ percentile. The classroom teacher believed that Joey's ability to memorize and follow visual cues were important factors relating to his success. She likewise attributed Aaron's performance, at least in part, to his being the last student to receive the intervention. Although both students qualified for participation in 
the study on the basis of skill-based assessment, differences in participant performance suggest that it may be important to consider factors other than skill level when planning for and accurately projecting intervention outcomes.

An additional limitation relates to the similarity of prices in the intervention and postintervention phases. Each price was changed based on its generalizability to one part of the problem (penny, nickel, dime, quarter, or dollar bill). In other words, the price was altered either by one penny, one nickel, one dime, one quarter, or one dollar. Problem presentation during the intervention phase was also restricted to one five-item exemplar. It is acknowledged that repeated presentations of the same academic task can have a "facilitative effect" on participant performance (Gast, 2010). Practice effects thus present a confounding variable, potentially influencing the outcome of the study. Instituting greater variability among visual stimuli during task presentation may have strengthened the results of the study in terms of the inferences made.

Finally, although social validation data were collected, the way in which the information was gathered represents a final limitation. A more indirect method of assessing consumer satisfaction such as documenting students' voluntary and/or continued use of the VSM procedure following the study's completion would have strengthened the interpretation of the results. Future research would do well to examine areas noted in this section.

\section{Implications for Practice}

Current findings suggested that VSM via an iPad could be an effective option for teachers implementing interventions to improve the academic performance of students with autism and intellectual disabilities, including those receiving educational services in special education classrooms. Moreover, the results of the study could have important implications for educators delivering instruction to students of varied abilities in broadly diverse settings. Importantly, the 
study's outcome addressed the current need to extend the literature base in the use of VSM to strengthen academic skills instruction (Prater, Carter \& Hitchcock, 2012).

Specifically, the VSM intervention allowed participants to independently access the technology and prompt themselves through the completion of functional math skills without teacher assistance. The results, therefore, have implications for educators in terms of innovative methods that may be feasibly implemented without high levels of teacher supervision. The intervention is less labor intensive than some instructional procedures, potentially freeing up instructor time and allowing multiple students to receive individualized assistance. Furthermore, the invention supports independence and the development of quality work habits, important outcomes for all learners, including students with autism.

An immediate and abrupt change in student performance was observed each time the video model was introduced. The data therefore, demonstrate the efficacy of using visual stimuli to enhance skill acquisition when working with students with autism and limited cognitive ability. The classroom teacher reported that study participants appeared to be excited to use the iPad and watch the VSM. Anecdotal information indicated that students with serious behavior issues (i.e., aggression, language, fidgeting, inattention) remained on-task to a greater extent than when the technology was unavailable. Results suggest that VSM improved students' academic skills and may have increased their task engagement.

Additional applications of VSM could benefit students with disabilities in a number of ways, allowing learners to engage in a wide array of academic and work related tasks. The increased educational opportunity could lead to improved self-efficacy, resulting in better social and academic outcomes over the lifespan. Positive intervention effects, generalized across behaviors, contexts, and time could likewise significantly impact future educational practice. 
Interventions such as the one evaluated in the present study may help adolescents with disabilities access the core curriculum and achieve improved long-term outcomes. However, further research is needed to explore the efficacy of using interventions such as VSM to extend the literature base in academic core instruction for all students with disabilities (Browder \& Cooper-Duffy, 2003).

\section{Implications for Future Research}

Systematic replications of the study could be helpful in examining a number of research questions. For example, future research would do well to assess the positive effects of VSM via an iPad on dependent variables such as on-task behavior during academic instruction. Anecdotal data collected as part of the current research suggested that measuring students' on-task behavior during regular math instruction and comparing the level of performance to the students' behavior during VSM intervention could provide useful information for teachers. Assessing different math skills, such as budgeting and time management, could also be beneficial. Additional research is likewise needed to examine the use of VSM via an iPad to teach students with autism and intellectual disabilities a variety of academic subjects, such as science, reading, and writing. The investigation of mathematics instruction incorporating similar technology in community and post high school settings is also warranted. Generalization of the methods to involve teachers, community workers, family members, and other school professionals is an additional area deserving further investigation. A potential residual effect in relation to improved on task behavior and academic performance was observed following the removal of VSM. Because the apparent improvements may have been associated with the intervention, further investigation of unplanned effects is recommended. 


\section{Conclusion}

Results of the study clearly suggest that VSM via an iPad may be an effective way to deliver academic content to adolescent students with autism and intellectual disabilities. Although present findings are promising, future research is needed to establish VSM as an evidence-based practice for students with disabilities and in a variety of academic contexts (Prater et al., 2012). 


\section{References}

American Psychiatric Association. (2000). Diagnostic and statistical manual of mental disorders (4th ed., text rev.). Washington, DC: Author.

Bellini, S., \& Akullian, J. (2007). A meta-analysis of video modeling and video self-modeling interventions for children and adolescents with autism spectrum disorders. Exceptional Children, 73(3), 264-287.

Bracken, B. A., \& McCallum, R. (1998). Universal Nonverbal Intelligence Test. Austin, TX: Pro-ed.

Brigance, A. H. (1999). Brigance Diagnostic Comprehensive Inventory of Basic Skills-Revised [Instrument]. North Billerica, MA: Curriculum Associates.

Browder, D. M., \& Cooper-Duffy, K. (2003). Evidence-based practices for students with severe disabilities and the requirement for accountability in "No Child Left Behind." Journal of Special Education, 37(3), 157-163.

Buggey, T. (2007). “A picture is worth...": Video self-modeling applications at school and home. Journal of Positive Behavior Interventions, 9(3), 151-158.

Buggey, T., Toombs, K., Gardener, P., \& Cervetti, M. (1999). Training responding behaviors in students with autism: Using videotaped self-modeling. Journal of Positive Behavior Interventions, 1, 205-214.

Charlop-Christy, M., \& Daneshvar, S. (2003). Using video modeling to teach perspective taking to children with autism. Journal of Positive Behavior Interventions, 5(1), 12-21.

Cihak, D., \& Bowlin, T. (2009). Using video modeling via handheld computers to improve geometry skills for high school students with learning disabilities. Journal of Special Education Technology, 24(4), 17-29. 
Cihak, D., Fahrenkrog, C., Ayres, K. M., \& Smith, C. (2010). The use of video modeling via a video iPod and a system of least prompts to improve transitional behaviors for students with autism spectrum disorders in the general education classroom. Journal of Positive Behavior Interventions, 12(2), 103-115.

Cihak, D. F., Kessler, K. B., \& Alberto, P. A. (2007). Generalized use of a handheld prompting system. Research in Developmental Disabilities, 28(4), 397-408. doi:

10.1016/j.ridd.2006.05.003

Cizek, G. J. (2001). Review of Developmental Indicators for the Assessment of Learning--Third Edition. In B. S. Plake \& J. C. Impara (Eds.), Fourteenth mental measurements yearbook (pp. 394-398). Lincoln, NE: Buros Institute of Mental Measurement.

Clare, S. K., Jenson, W. R., Kehle, T. J., \& Bray, M. A. (2000). Self-modeling as a treatment for increasing on-task behavior. Psychology in the Schools, 37, 517-522.

“Common Core State Standards.” n.d. Retrieved June 9, 2011, from http://www.corestandards.org/assets/CCSSI_Math\%20Standards.pdf

Dowrick, P. W. (1999). A review of self-modeling and related interventions. Applied \& Preventive Psychology, 8, 23-39.

Gast, D. L. (2010). Single Subject Research Methodology in Behavioral Sciences. New York: Routledge.

Good, R. H., \& Kaminski, R. A. (Eds.). (2002). Dynamic Indicators of Basic Early Literacy Skills (6th ed.). Eugene, OR: Institute for the Development of Educational Achievement. Available: http://dibels.uoregon.edu/.

Hartley, E.T., Bray, M. A., \& Kehle, T. J. (1998). Self-modeling as an intervention to increase student classroom participation. Psychology in the Schools, 35, 363-372. 
Hitchcock, C. H., Dowrick, P. W., \& Prater, M. A. (2003). Video self-modeling intervention in school-based settings: A review. Remedial and Special Education, 24(1), 36-45,56.

Kazdin, A. E. (1982). Single-case research designs: Methods for clinical and applied settings. New York: Oxford University Press.

Knight, V. F., Smith, B. R., Spooner, F., \& Browder, D. (2011). Using explicit instruction to teach science descriptors to students with autism spectrum disorders. Journal of Autism and Developmental Disorders, Online First, 19 April 2011. doi: 10.1007/s10803-011$1258-1$

Mechling, L. (2005). The effect of instructor-created video programs to teach students with disabilities: A literature review. Journal of Special Education Technology, 20(2), 25-36.

Odom, S. L., Brantlinger, E., Gersten, R., Horner, R. H., Thompson, B., \& Harris, K. R. (2005). Research in special education: Scientific methods and evidence-based practices. Exceptional Children, 71(2), 137-148.

Parker, R. I., Vannest, K. J., \& Brown, L. (2009). The improvement rate difference for singlecase research. Exceptional Children, 75(2), 135-150.

Possell, L. E., Kehle, T. J., McLoughlin, C. S., \& Bray, M. A. (1999). Self-modeling as an intervention to reduce disruptive classroom behavior. Cognitive and Behavioral Practice, 6(2), 99-105. doi: 10.1016/S1077-7229(99)80017-0

Prater, M. A., Carter, N. J., Hitchcock, C. H., \& Dowrick, P. (2012). Video self-modeling to improve academic performance: A literature review. Psychology in the Schools, 49(1), 71-81. doi:10.1002/pits.20617

Prater, M. A., Carter, N. J., \& Hitchcock, C. H. (2011). Video self-modeling to improve academic performance: A literature review. Manuscript submitted for publication. 
Schunk, D. H., \& Hanson, A. R. (1989). Self-modeling and children's cognitive skill learning. Journal of Educational Psychology, 81(2), 155-163. doi:10.1037/0022-0663.81.2.155

Shipley-Benamou, R., Lutzker, J. R., \& Taubman, M. (2002). Teaching daily living skills to children with autism through instructional video modeling. Journal of Positive Behavior Interventions, 4(3), 165-188.

Tawney, J. W., \& Gast, D. L. (1984). Single-subject research in special education. Columbus, $\mathrm{OH}$ : Charles E. Merrill.

U. S. Department of Education. (2008). Thirtieth annual report to Congress on the implementation of the Individuals with Disabilities Education Act. Washington, DC: Author.

Wechsler, D. (2003). Wechsler Intelligence Scale for Children-Fourth Edition. San Antonio, TX: The Psychological Corporation.

Wolf, M. M. (1978). Social validity: The case for subjective measurement or how applied behavior analysis is finding its heart. Journal of Applied Behavior Analysis. 11, 203-214.

Woodcock, R. W., McGrew, K. S., \& Mather, N. (2001). Woodcock-Johnson III Tests of Cognitive Abilities. Itasca, IL: Riverside Publishing. 
Table 1

Student Assessment Results

\begin{tabular}{lccccc}
\hline Student & Age & $\begin{array}{c}\text { Reading } \\
\text { Grade } \\
\text { Level }\end{array}$ & $\begin{array}{c}\text { Disability } \\
\text { Classification }\end{array}$ & $\begin{array}{c}\text { IQ } \\
\text { Test }\end{array}$ & Full Scale IQ \\
\hline Joey & 13 & 4 & Autism & UNIT & 85 \\
Will & 14 & 3 & Autism & UNIT & 76 \\
Ryan & 15 & 3 & Autism & WJIII & 61 \\
Aaron & 13 & 3 & Intellectual & WISC IV & 66 \\
\hline
\end{tabular}

Note. Disability classifications obtained from educational classifications listed on each participant's IEP. IQ scores were obtained from "Vineland II Adaptive Behavior Scales, Second Edition," Pearson Education. WJIII = Woodcock Johnson III Tests of Cognitive Ability; WISC IV $=$ Wechsler Intelligence Scales for Children, Fourth Edition; UNIT = Universal Nonverbal Intelligence Test. Reading level was assessed using the DIBELS = Dynamic Indicators of Basic Early Literacy Skills. 

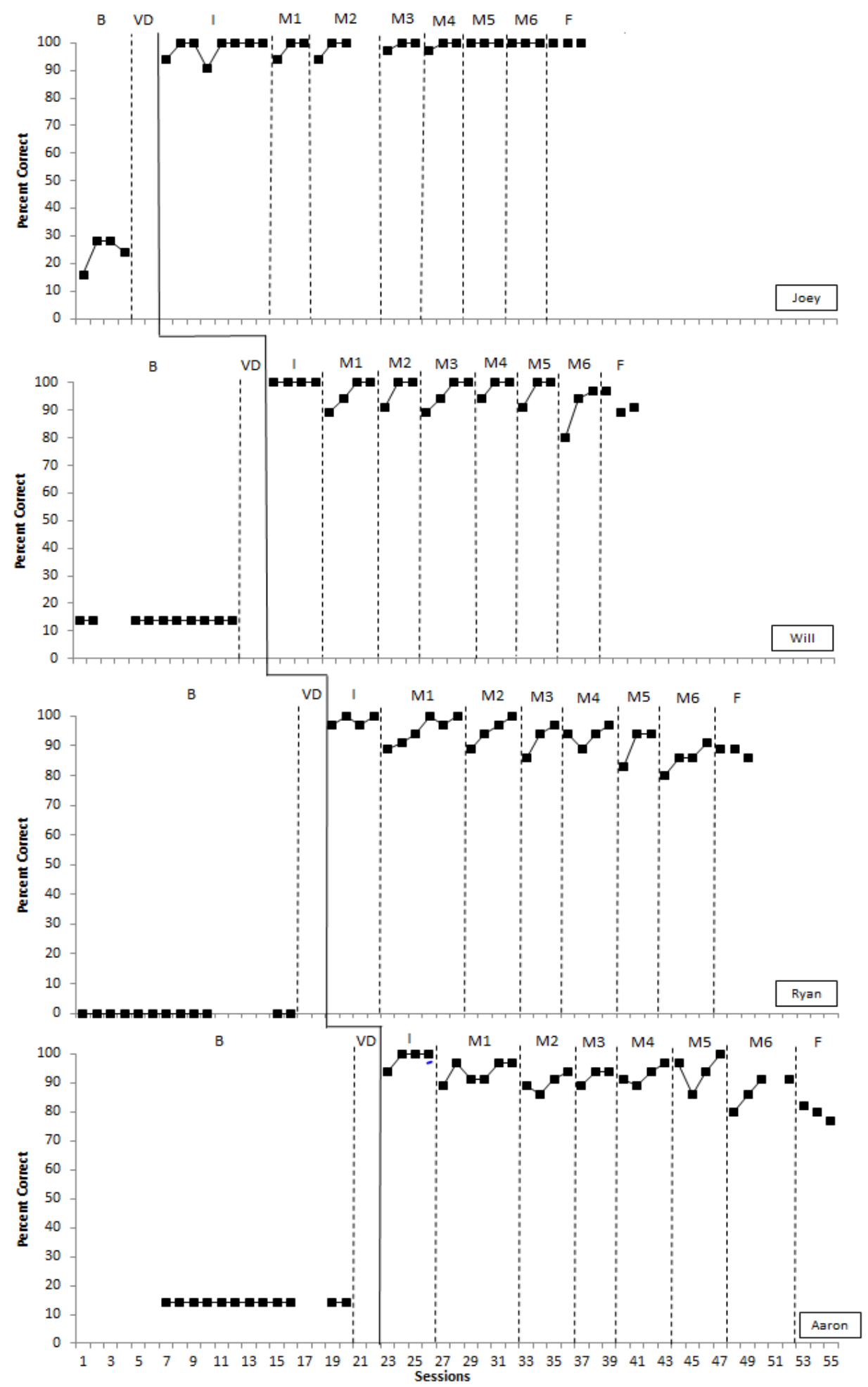

B - Baseline VD - Video Development

I - Intervention M1 - Maintenance \#1 M2 - Maintenance \#2 M3 - Maintenance \#3 M4 - Maintenance \#4 M5 - Maintenance \#5 M6 - Maintenance \#6 F - Follow-up

Figure 1. Percentage of math story problem steps completed accurately for all participants. 